\title{
Higher adiponectin concentrations are associated with reduced metabolic syndrome risk independently of weight status in Brazilian adolescents
}

\author{
Karen Sparrenberger ${ }^{1 *}$, Mariana Sbaraini², Felipe Vogt Cureau ${ }^{1,3}$, Gabriela Heiden Teló $^{2}$, Luciana Bahia ${ }^{2}$ \\ and Beatriz D. Schaan 1,3,4
}

\begin{abstract}
Objective: To evaluate the association between adiponectin concentrations and metabolic syndrome (MetS) risk and to investigate if this association is independent of weight status in adolescents.

Methods: Adiponectin concentrations and MetS risk were assessed in 4546 Brazilian adolescents (12-17 years old) enrolled in The Study of Cardiovascular Risks in Adolescents ("ERICA"), a cross-sectional multicenter study in Brazil. For analyses, adiponectin was categorized in sex and age-specific quartiles and MetS risk was expressed as a continuous score, calculated as the average of the standardized values (z-score) of the five MetS components. Multiple linear regression models were used to investigate the association between the quartiles of adiponectin and MetS risk.

Results: Adiponectin was inversely associated with waist circumference and log-transformed triglycerides, and positively associated with $\mathrm{HDL}-\mathrm{c}$. We also observed an inverse association between adiponectin concentrations and MetS risk. After adjustment for sociodemographic variables, physical activity, skipping breakfast and body mass index (BMI), higher quartiles of adiponectin remained inversely associated with waist circumference and MetS risk. A direct association between adiponectin and HDL-c was also observed. In further analysis, the sample was stratified by weight status and an inverse association between quartiles of adiponectin and MetS risk was observed in both normal weight and overweight/obese adolescents.
\end{abstract}

Conclusion: Higher adiponectin concentrations were independently and inverse associated with MetS risk in Brazilian adolescents, even after adjusting for BMI. These results were similar in normal weight and overweight/obese adolescents, suggesting that adiponectin may play a role in early development of MetS.

Keywords: Adiponectin, Metabolic syndrome, Adolescents, Pediatric, Obesity

\footnotetext{
*Correspondence: sparrenberger.k@gmail.com

${ }^{1}$ Postgraduate Program in Endocrinology, Universidade Federal do Rio Grande do Sul-Hospital de Clínicas de Porto Alegre, Rua Ramiro Barcelos

2350, Prédio 21, $6^{\circ}$ andar, Porto Alegre, RS 90035-003, Brazil

Full list of author information is available at the end of the article
} 


\section{Introduction}

Metabolic syndrome (MetS) is a constellation of classical cardio-metabolic risk factors, including abdominal obesity, hypertension, dyslipidemia and hyperglycemia $[1,2]$. The prevalence of MetS in the pediatric population has increased considerably in recent years and it has been associated with an increased risk for development of cardiovascular diseases during life [3, 4].

The etiology of MetS is complex and still not completely elucidated, thus different mechanisms remain under investigation [5]. In this context, adipokines have been studied as potential factors that play a role in the development of MetS [6, 7]. One of the most studied adipokines is adiponectin, which is produced in abundance by adipose tissue and is responsible for modulation of several metabolic processes, such as glucosec homeostasis and oxidation of fatty acids. In addition, adiponectin also has anti-inflammatory properties $[8$, 9].

In a previous publication, we described the adiponectin distribution and showed that lower levels of this adipokine were associated with general and abdominal obesity among Brazilian adolescents [10]. In metabolically unhealthy subjects, especially in the presence of obesity, circulating adiponectin is also reduced [11-13]. In adolescents, lower concentrations of adiponectin were observed in the presence of MetS [11, 14], as well as an inverse association with most of MetS components [15, 16]. However, the majority of the studies that investigated the association between adiponectin concentrations and MetS were performed in small and homogeneous samples (i.e. overweight/obese adolescents) [17, 18]. Therefore, studies addressing the relationship between adiponectin and MetS in a representative population of adolescents are scarce, especially those aiming to investigate if that association is independent of weight status [19].

Thus, in order to better understand this interaction, we developed a study based on data from the Study of Cardiovascular Risk in Adolescents ("ERICA") to evaluate the association between adiponectin concentrations and MetS risk in a large sample of Brazilian adolescents and also to investigate if this association is independent of weight status.

\section{Methods}

\section{Design and sample}

ERICA is a national, school-based, cross-sectional, multicenter study conducted from 2013 to 2014, which evaluated the prevalence of cardiovascular risk factors in Brazilian adolescents (12 to 17 years old) who lived in cities with more than 100,000 inhabitants.
Sample size calculation and the sampling process have been fully described previously [20]. Briefly, the sample was divided into 32 strata, comprised of 27 capitals of Brazilian states and five more strata composed by other cities with more than 100,000 inhabitants from each of the five geographic macroregions of Brazil. Stratification was done according to three categories: schools (public or private), grade (seventh, eighth and ninth grade of Elementary and first, second and third grade of High School) and shift (morning or afternoon) of the classrooms. All adolescents from sampled classrooms were eligible to enter in the study. Sampling weight was calculated by the products of the inverse probabilities of inclusion in each selection stage and was calibrated by age and sex, considering the estimated number of adolescents from schools located in the geographic strata included in the study.

In this study, the sample consists of 4546 adolescents who attended school at morning classes in four Brazilian capitals: Brasília, Fortaleza, Porto Alegre and Rio de Janeiro. These cities are located in four of the five Brazilian macroregions, and the sample was representative at a municipality level. A full description of the study design, data collection and blood sampling is available elsewhere $[21,22]$.

ERICA's protocol was approved by Research Ethics Committees in all 27 Federation units in Brazil. Adolescents were invited at schools to participate in the study, and all those enrolled agreed in writing before the data collection. In addition, we collected a written informed consent signed by the parent or legal guardian of the participant.

\section{Adiponectin measurement}

Serum total adiponectin concentrations $(\mu \mathrm{g} / \mathrm{ml})$ were measured by enzyme-linked immunosorbent assay (ELISA) kit from Invitrogen ${ }^{\circledR}$ (KHP0041) with a sensitivity of $0.001 \mu \mathrm{g} / \mathrm{ml}$. Intra and inter-assay coefficients of variation were $<5 \%$, following the manufacturer instructions. Laboratory analyses were performed by a single laboratory using frozen serum $\left(-80^{\circ} \mathrm{C}\right)$ and following a standardized protocol [21]. Thereafter, for data analyses, adiponectin concentrations were categorized into sex and age-specific quartiles (Additional file 1: Table S1).

\section{MetS components}

Waist circumference was measured using an inelastic measuring tape. The measurement was done horizontally, at half the distance between the iliac crest and the lower costal margin. Systolic and diastolic blood pressure were measured using an automatic oscillometric device (Omron $\left.{ }^{\circledR} 705-\mathrm{IT}\right)$, previously validated for use in youth [20]. Three consecutive measures were taken in the 
student's right arm after 5 min sitting in a quiet position, and with an interval of at least $3 \mathrm{~min}$ between each measure. The second and third blood pressure readings were averaged and used in the analyses.

All participants were asked to refrain from food for 10-12 $\mathrm{h}$ before blood sampling. Compliance with the overnight fasting was determined by questionnaire before venipuncture. Fasting blood samples were collected for measurements of glucose, high-density lipoprotein cholesterol (HDL-c) and triglycerides. All blood samples were analyzed by a single laboratory following a standardized protocol [21].

\section{MetS risk z-score}

Before data analyses, all MetS components were standardized to the mean ( $\mathrm{z}$-score) by gender and age. Broadly based on the definition proposed by the International Diabetes Federation (IDF) [23], we constructed a continuously distributed MetS risk z-score (MetS-z), approach which was widely reported in the literature [24-26]. This variable was derived by standardizing and then summing the following continuously distributed MetS components: waist circumference, high blood pressure (average of systolic blood pressure and diastolic blood pressure), hyperglycemia (fasting plasma glucose) and dyslipidemias (inverted fasting HDL-c, and log-transformed triglycerides). Higher values on the MetS- $z$ were indicative of a poorer metabolic profile and higher risk for development of MetS [24, 26].

\section{Covariates}

The following variables were examined as covariates: study centers (Rio de Janeiro, Porto Alegre, Fortaleza and Brasília), sex, age groups (12-13, 14-15 and 16-17 years), skin color (white, black and mixed/yellow/native), and type of school (public or private). An economic index, similar to which was used in Brazilian demographic census, was used to assess economic status [27]; it considered possession of certain goods and the presence of a housekeeper at home. Thereafter, the index was categorized in tertiles.

Skipping breakfast (always/very often) was self-reported and considered an indicator of unhealthy eating habits. Time spent in moderate-to-vigorous physical activity was assessed using an adapted version of the Self-Administered Physical Activity Checklist Questionnaire [28], cross-culturally adapted and validated for Brazilian adolescents [29]. To determine the weekly amount of time spent in physical activity, we multiplied self-reported duration and frequency for each activity listed and then dichotomized it in $<300$ or $\geq 300 \mathrm{~min} /$ week.
Trained researchers measured the clinical variables. Height was measured twice using a portable stadiometer with a 0.1 variation, and the mean of the two values obtained was considered in the analyses. Weight was measured using a digital scale in light clothing. Body mass index (BMI) was calculated using the standardized formula $\left[\mathrm{BMI}=\right.$ weight $\left.(\mathrm{kg}) / \mathrm{height}^{2}\left(\mathrm{~m}^{2}\right)\right]$. The World Health Organization reference curves were used to classify adolescents with normal weight (BMI z-score $\leq 1)$, overweight (BMI z-score $>1$ and $\leq 2$ ) and obesity (BMI $z$-score $>2$ ) [30]. Overweight and obesity were then combined into one category.

\section{Statistical analysis}

Fasting triglycerides were logarithmically transformed owing to their skewed distributions (geometric mean and $95 \%$ confidence intervals $(95 \% \mathrm{CI})$ are presented in the results). Adiponectin concentrations were described by median values and $95 \%$ CI. Thereafter, this variable was categorized according to sex and age-specific quartiles (Additional file 1: Table S1).

Initially, we assessed the distribution of investigated cardio-metabolic risk factors according to the quartiles of adiponectin, and the linear trends were evaluated by Wald's test. Associations between quartiles of adiponectin and MetS-z and MetS components were investigated by multiple linear regressions. Our first model was adjusted for sex, age, skin color and socioeconomic status. These variables were kept in the second model in addition to physical activity and skipping breakfast. In the final adjusted model, BMI was included as a potential confounder (adiposity-adjustment).

The global adjustment of the models was evaluated. We did not find evidence of multicollinearity into the models, even when BMI was included. The adiponectin and sex interaction for the association with MetS- $z$ and MetS components was tested using a multiplicative approach. In further analyses, we investigated the association between quartiles of adiponectin and MetS-z after stratifying the sample for weight status, considering the possibility that this association could be modified in the presence of overweight/obesity. We also calculated a MetS-z score without the adiposity component (i.e., waist circumference) to examine whether the association between the main exposure and MetS-z is mediated by adiposity.

To obtain population-representative findings, analyses were conducted using sample weights for ERICA, which accounted for the complex survey design [20]. All tests were two-tailed. The analyses were performed using Stata version 14 (StataCorp, College Station, TX, USA). 
Table 1 Characteristics of study participants, ERICA 2013$2014(n=4546)$

\begin{tabular}{|c|c|}
\hline Characteristics & $\begin{array}{l}\text { Weighted mean } \\
\text { or frequency }(95 \% \\
\mathrm{Cl})\end{array}$ \\
\hline \multicolumn{2}{|l|}{ Study centers, $\%$} \\
\hline Fortaleza & $24.4(23.1,25.6)$ \\
\hline Rio de Janeiro & $32.8(31.4,34.1)$ \\
\hline Porto Alegre & $18.1(31.4,34.1)$ \\
\hline Brasília & $24.7(23.5,26.0)$ \\
\hline Female sex, \% & $61.2(59.8,62.6)$ \\
\hline Age, years & $14.9(14.8,14.9)$ \\
\hline \multicolumn{2}{|l|}{ Skin color, \% } \\
\hline White & $39.9(36.5,43.4)$ \\
\hline Black & $9.2(7.5,11.3)$ \\
\hline Others (mixed, native or yellow) & $50.9(48.2,53.5)$ \\
\hline Public School, \% & $66.5(55.9,75.6)$ \\
\hline \multicolumn{2}{|l|}{ Socioeconomic status (tertile), \% } \\
\hline First (poorest) & $36.9(33.1,40.9)$ \\
\hline Second & $27.6(25.3,30.1)$ \\
\hline Third & $35.5(30.6,40.7)$ \\
\hline Skip breakfast, $\%$ & $51.0(48.2,53.9)$ \\
\hline Physical inactivity, \% & $47.5(44.8,50.3)$ \\
\hline Body mass index, $\mathrm{kg} / \mathrm{m}^{2}$ & $21.7(21.4,21.9)$ \\
\hline Waist circumference, $\mathrm{cm}$ & $72.8(72.1,73.6)$ \\
\hline Systolic BP, mmHg & $110.8(110.1,111.5)$ \\
\hline Diastolic BP, mmHg & $65.8(65.3,66.3)$ \\
\hline Mean $\mathrm{BP}, \mathrm{mmHg}$ & $80.8(80.2,81.3)$ \\
\hline $\mathrm{HDL}-\mathrm{c}, \mathrm{mg} / \mathrm{dl}$ & $47.7(47.2,48.3)$ \\
\hline Triglycerides $(\log )^{a}, \mathrm{mg} / \mathrm{dl}$ & $70.3(69.0,71.5)$ \\
\hline Fasting plasma glucose, mg/dl & $86.9(86.5,87.4)$ \\
\hline Metabolic syndrome, z-score & $-0.05(-0.22,0.13)$ \\
\hline Adiponectin ${ }^{b}, \mu \mathrm{g} / \mathrm{ml}$ & $13.4(12.8,14.00)$ \\
\hline
\end{tabular}

$\mathrm{BP}$, blood pressure; $\mathrm{HDL}-\mathrm{C}$, high density lipoprotein cholesterol

a Triglycerides were log transformed and reported as geometric mean and $95 \%$

${ }^{\mathrm{b}}$ Adiponectin was reported as median and $95 \% \mathrm{Cl}$

\section{Results}

The analysed sample was composed of 4546 adolescents. Table 1 shows the main characteristics of the sample. Most adolescents were female and students from public schools. The mean age was $14.9(\mathrm{SD}=1.5)$ years old. Overall, $19.1 \%$ and $9.1 \%$ of the adolescents were categorized as overweight and obese, respectively. According to the IDF criteria for youth, the prevalence of metabolic syndrome in this sample was $2.0 \%$ (95\% CI 1.6\%, 2.5\%), similar in boys and girls.

The median of adiponectin was lower in those with overweight/obesity $(11.6 \mu \mathrm{g} / \mathrm{ml} ; 95 \%$ CI $10.6,12.6)$ compared to those with normal weight $(14.3 \mu \mathrm{g} / \mathrm{ml}, 95 \%$ CI 13.6, 15.0). The means of MetS-z were -1.1 (95\% CI
$-1.2,-0.9)$ and $2.3(95 \%$ CI 2.0, 2.6) in adolescents with normal weight and overweight/obesity, respectively.

We did not find any indicative of interaction between sex and adiponectin concentrations for the association with MetS-z ( $p$ value for interaction $>0.8$ ) or MetS components ( $\mathrm{p}$-value for interaction $>0.5$ ), thus all analyses were performed for the overall sample. The values of sex and age-specific quartiles of adiponectin are presented in the Additional file 1: Table S1. The cut-off points for those in the reference group (1st quartile) were lower among boys compared with girls and decreased with age in both sexes.

Table 2 shows the means of the MetS-z and MetS components according to the quartiles of adiponectin. Lower values of waist circumference, triglycerides and MetS- $\mathrm{z}$, as well as increased HDL-c concentrations were observed in the upper quartiles of adiponectin. However, no variations in blood pressure or fasting plasma glucose values were observed across quartiles of adiponectin.

Table 3 shows the associations between adiponectin levels, MetS-z and MetS components. In the first (sociodemographic-adjusted) and second (behavior-adjusted) models, adiponectin concentrations were inversely associated with waist circumference, triglycerides and MetS-z. In addition, HDL-c concentrations increased through the quartiles of adiponectin. After including BMI in the model (adiposityadjusted) and despite a reduction in the strength of the associations, the coefficients remained significant for HDLc, waist circumference and MetS-z for those adolescents in the top quartile of adiponectin. In sensitivity analysis, waist circumference was removed from the outcome to investigate the possibility that obesity may drive the observed association. The associations were somewhat attenuated, but results were materially unchanged.

The associations between quartiles of adiponectin and the MetS- $\mathrm{z}$ according to weight status are presented in Fig. 1. The MetS-z was reduced in higher quartiles of adiponectin, in both normal weight and overweight/obese adolescents. However, the association observed seems to be slightly more pronounced among adolescents with overweight/obesity (Panel b) when compared with normal weight youth (Panel a).

\section{Discussion}

In this study, we aimed to evaluate the association between adiponectin concentrations and MetS-z. Our findings showed a significant and inverse association between higher levels of adiponectin and MetS-z independently of potential confounders, including BMI, in Brazilian adolescents. Additionally, after splitting the sample by weight status, the association between adiponectin and MetS-z remained unchanged in both normal weight and overweight/obese adolescents. 
Table 2 Mean and $95 \% \mathrm{Cl}$ of metabolic syndrome risk score and its individual components according to quartiles of adiponectin, ERICA 2013-2014

\begin{tabular}{|c|c|c|c|c|c|}
\hline & \multicolumn{4}{|c|}{ Quartiles of adiponectin } & \multirow[t]{2}{*}{$p$ for trends } \\
\hline & First $(n=1092)$ & Second $(n=1101)$ & Third $(n=1112)$ & Fourth $^{b}(n=1241)$ & \\
\hline Waist circumference, $\mathrm{cm}$ & $74.7(73.8,75.6)$ & $73.5(73.4,75.6)$ & $72.2(71.2,73.3)$ & $70.9(70.1,71.7)$ & $<0.001$ \\
\hline Systolic BP, mmHg & $111.3(110.2,112.4)$ & $110.8(109.6,112.1)$ & $111.0(109.8,112.2)$ & $110.1(109.1,111.1)$ & 0.157 \\
\hline Diastolic BP, mmHg & $65.8(65.0,66.6)$ & $65.9(65.1,66.7)$ & $65.9(65.1,66.7)$ & $65.5(64.9,66.2)$ & 0.622 \\
\hline Mean $\mathrm{BP}, \mathrm{mmHg}$ & $81.0(80.1,81.8)$ & $80.9(80.0,81.8)$ & $80.9(80.0,81.8)$ & $80.4(79.6,81.1)$ & 0.334 \\
\hline Triglycerides ${ }^{\mathrm{a}}(\mathrm{log}), \mathrm{mg} / \mathrm{dl}$ & $71.9(69.5,74.3)$ & $72.1(69.4,74.9)$ & $70.1(67.7,72.6)$ & $67.1(65.1,69.1)$ & 0.004 \\
\hline $\mathrm{HDL}-\mathrm{c}, \mathrm{mg} / \mathrm{dl}$ & $46.6(45.9,47.3)$ & $46.3(45.5,47.1)$ & $48.1(47.2,49.1)$ & $50.0(48.9,50.9)$ & $<0.001$ \\
\hline Fasting plasma glucose, mg/dl & $87.2(86.4,88.0)$ & $87.1(86.4,87.8)$ & $86.9(86.2,87.6)$ & $86.5(85.9,87.2)$ & 0.222 \\
\hline MetS-z, z-score & $0.35(0.14,0.57)$ & $0.24(-0.04,0.53)$ & $-0.12(-0.41,0.18)$ & $-0.66(-0.89,-0.43)$ & $<0.001$ \\
\hline $\begin{array}{l}\text { MetS-z without waist circumfer- } \\
\text { ence, z-score }\end{array}$ & $0.15(-0.03,0.34)$ & $0.18(-0.06,0.42)$ & $-0.06(-0.28,0.16)$ & $-0.46(0.64,-0.28)$ & $<0.001$ \\
\hline
\end{tabular}

BP, blood pressure; HDL-c, high density lipoprotein cholesterol; MetS-z, metabolic syndrome risk Z-score

a Triglycerides was log transformed and reported as geometric mean and $95 \% \mathrm{Cl}$

${ }^{\mathrm{b}}$ Highest values

The role of adiponectin in the pathogenesis of MetS remains controversial. Other authors have hypothesized that adiponectin concentrations are influenced by several traditional risk factors for Mets (i.e. sex, age, diet, physical activity, etc.), and that those risk factors may induce adiponectin resistance. Abnormal concentrations of adiponectin are related to low grade inflammation, which represents a key factor in the development of MetS, and it is directly associated with insulin resistance and regulation of adipose tissue distribution [7].

Regarding each individual component of MetS, in our models adjusted for sociodemographic and behavioral characteristics, adiponectin concentrations were positively associated with HDL-c and inversely associated with waist circumference and triglycerides. After adjusting for BMI, only the association with triglycerides overlapped the reference value. In accordance to the literature, adiponectin seems to act on reduction of triglycerides concentrations, increasing glucose uptake by the skeletal muscle and thus increasing HDL-c through hepatic lipase activity [31]. Previous study with adolescents also showed correlations between adiponectin and HDL-c, triglycerides and blood pressure [14, 32, 33].

In this study the concentrations of adiponectin were inversely associated with MetS-z even after adjustment for BMI, although not without attenuation in strength of the association. To use of MetS-z instead of dichotomous criteria can be powerful, however it is difficult to interpret whether changes in $\beta$ coefficients are clinically meaningful. However, if we consider that all cardiometabolic risk factors involved in MetS-z are continuously associated with cardiovascular risk and that a good health is expected in this age group, it is possible to consider that any significant change in $\beta$ coefficients are relevant in terms of public health.

The association between adiponectin concentrations and MetS has been described before, especially in overweight populations (24-26), but only a few studies have investigated whether this association is independent or not of adiposity [32, 34]. In a Mediterranean pediatric cohort $(\mathrm{n}=1138)$, adiponectin was no longer significantly associated with higher number of MetS components after adjustment for BMI, although the prevalence of MetS in this study was very low (0.7\%) and was only observed in youth with obesity [32]. On the Identification and prevention of Dietary and lifestyle induced health Effects In Children and infants study (IDEFICS), after inclusion of BMI in the model, the association between adiponectin and MetS was no longer observed, suggesting that this relation may be mediated by adiposity [11]. Finally, other authors observed that low concentrations of adiponectin were prospectively associated with a poor cardiometabolic profile, but only among overweight youth [35].

On the other hand, adiponectin was associated with MetS in Chinese adolescents [15] and with several MetS components in a sample of Puerto Rican youth [36], and, in both studies, these results were independent of adiposity. These data are in line with our results, suggesting that adiponectin may play a role in the prevention of MetS. Our study extends these previous observations while including a large and representative sample of a multiethnic population of adolescents. In sensitivity analysis, waist circumference was removed from the outcome to investigate the possibility that obesity may drive the observed association; however, it was only partially confirmed because the association was attenuated but did 
Table 3 Association between quartiles of adiponectin with metabolic syndrome risk score and its individual components, ERICA 2013-2014

\begin{tabular}{|c|c|c|c|c|c|c|c|c|}
\hline \multirow[t]{2}{*}{ Clinical outcomes } & \multicolumn{7}{|c|}{ Quartiles of adiponectin } & \multirow[t]{2}{*}{$p$ for trends } \\
\hline & $\begin{array}{l}\text { First }(n=1092) \\
\beta(95 \% \mathrm{Cl})\end{array}$ & \multicolumn{2}{|c|}{ Second $(n=1101)$} & \multicolumn{2}{|c|}{ Third $(n=1112)$} & \multicolumn{2}{|c|}{ Fourth $(n=1241)^{b}$} & \\
\hline \multicolumn{9}{|c|}{ Model 1: adjusted for sex, age, skin color and socioeconomic status } \\
\hline Waist circumference, $\mathrm{cm}$ & Ref & -1.65 & $(-2.98,-0.31)$ & -3.04 & $(-4.51,-1.56)$ & -3.83 & $(-5.20,-2.46)$ & $<0.001$ \\
\hline Systolic BP, mmHg & Ref & -1.04 & $(-2.29,0.21)$ & -0.75 & $(-2.05,0.55)$ & -1.16 & $(-2.70,0.37)$ & 0.220 \\
\hline Diastolic BP, mmHg & Ref & -0.07 & $(-0.97,0.84)$ & -0.10 & $(-1.08,0.88)$ & -0.31 & $(-1.33,0.71)$ & 0.586 \\
\hline Mean BP, mmHg & Ref & -0.39 & $(-1.33,0.55)$ & -0.32 & $(-1.35,0.71)$ & -0.60 & $(-1.72,0.53)$ & 0.381 \\
\hline Triglycerides $(\log )^{\mathrm{a}}, \mathrm{mg} / \mathrm{dl}$ & Ref & 0.001 & $(-0.05,0.05)$ & -0.03 & $(-0.07,0.02)$ & -0.07 & $(-0.12,-0.02)$ & 0.002 \\
\hline $\mathrm{HDL}-\mathrm{c}, \mathrm{mg} / \mathrm{dl}$ & Ref & -0.43 & $(-1.57,0.71)$ & 1.34 & $(0.15,2.53)$ & 3.05 & $(1.83,4.26)$ & $<0.001$ \\
\hline Fasting plasma glucose, mg/dl & Ref & 0.16 & $(-0.65,0.97)$ & -0.10 & $(-0.84,0.64)$ & -0.43 & $(-1.46,0.59)$ & 0.308 \\
\hline MetS-z, z-score & Ref & -0.16 & $(-0.45,0.14)$ & -0.55 & $(-0.86,-0.24)$ & -0.98 & $(-1.27,-0.69)$ & $<0.001$ \\
\hline $\begin{array}{l}\text { MetS-z without waist circumference, } \\
\text { z-score }\end{array}$ & Ref & 0.22 & $(-0.25,0.29)$ & -0.22 & $(-0.49,0.05)$ & -0.57 & $(-0.82,-0.32)$ & $<0.001$ \\
\hline \multicolumn{9}{|c|}{ Model 2: adjusted for variables in model 1 plus physical activity and skipping breakfast } \\
\hline Waist circumference, $\mathrm{cm}$ & Ref & -1.94 & $(-3.36,-0.53)$ & -3.28 & $(-4.84,-1.73)$ & -4.07 & $(-5.56,-2.58)$ & $<0.001$ \\
\hline Systolic BP, mmHg & Ref & -1.20 & $(-2.47,0.07)$ & -0.86 & $(-2.22,0.51)$ & -1.39 & $(-3.02,0.24)$ & 0.165 \\
\hline Diastolic BP, mmHg & Ref & -0.17 & $(-1.13,0.79)$ & -0.09 & $(-1.09,0.91)$ & -0.48 & $(-1.56,0.60)$ & 0.472 \\
\hline Mean $\mathrm{BP}, \mathrm{mmHg}$ & Ref & -0.51 & $(-1.49,0.47)$ & -0.35 & $(-1.41,0.72)$ & -0.78 & $(-1.98,0.41)$ & 0.293 \\
\hline Triglycerides $(\log )^{\mathrm{a}}, \mathrm{mg} / \mathrm{dl}$ & Ref & -0.01 & $(-0.06,0.04)$ & -0.04 & $(-0.09,0.01)$ & -0.08 & $(-0.12,-0.0-3)$ & 0.001 \\
\hline $\mathrm{HDL}-\mathrm{c}, \mathrm{mg} / \mathrm{dl}$ & Ref & -0.23 & $(-1.40,0.95)$ & 1.87 & $(0.59,3.15)$ & 3.02 & $(1.77,4.27)$ & $<0.001$ \\
\hline Fasting plasma glucose, mg/dl & Ref & -0.05 & $(-0.92,0.82)$ & -0.44 & $(-1.28,0.39)$ & -0.62 & $(-1.65,0.41)$ & 0.143 \\
\hline MetS-z, z-score & Ref & -0.29 & $(-0.60,0.02)$ & -0.71 & $(-1.06,-0.37)$ & -1.07 & $(-1.38,-0.75)$ & $<0.001$ \\
\hline $\begin{array}{l}\text { MetS-z without waist circumference, } \\
z \text {-score }\end{array}$ & Ref & -0.08 & $(-0.36,0.19)$ & -0.36 & $(-0.65,-0.07)$ & -0.63 & $(-0.88,-0.38)$ & $<0.001$ \\
\hline \multicolumn{9}{|c|}{ Model 3: adjusted for variables in models 2 plus body mass index } \\
\hline Waist circumference, $\mathrm{cm}$ & Ref & -0.42 & $(-0.97,0.14)$ & -0.27 & $(-0.86,0.31)$ & -0.81 & $(-1.52,-0.11)$ & 0.030 \\
\hline Systolic BP, mmHg & Ref & -0.28 & $(-0.58,1.01)$ & 0.96 & $(-0.28,2.20)$ & 0.59 & $(-0.78,1.95)$ & 0.218 \\
\hline Diastolic BP, mmHg & Ref & 0.23 & $(-0.72,1.17)$ & 0.68 & $(-0.21,1.57)$ & 0.37 & $(-0.62,1.37)$ & 0.373 \\
\hline Mean $\mathrm{BP}, \mathrm{mmHg}$ & Ref & 0.05 & $(-0.92,1.02)$ & 0.78 & $(-0.15,1.71)$ & 0.44 & $(-0.61,1.50)$ & 0.275 \\
\hline Triglycerides $(\log )^{\mathrm{a}}, \mathrm{mg} / \mathrm{dl}$ & Ref & 0.001 & $(-0.50,0.05)$ & -0.01 & $(-0.06,0.04)$ & -0.04 & $(-0.09,0.001)$ & 0.049 \\
\hline $\mathrm{HDL}-\mathrm{c}, \mathrm{mg} / \mathrm{dl}$ & Ref & -0.60 & $(-1.79,0.60)$ & 1.11 & $(-0.24,2.46)$ & 2.22 & $(0.98,3.47)$ & $<0.001$ \\
\hline Fasting plasma glucose, mg/dl & Ref & 0.03 & $(-0.85,0.91)$ & -0.28 & $(-1.13,0.58)$ & -0.43 & $(-1.49,0.63)$ & 0.318 \\
\hline MetS-z, z-scorec & Ref & 0.02 & $(-0.25,0.30)$ & -0.10 & $(-0.38,0.18)$ & -0.40 & $(-0.66,-0.14)$ & 0.005 \\
\hline $\begin{array}{l}\text { MetS-z without waist circumference, } \\
z \text {-score }{ }^{c}\end{array}$ & Ref & 0.10 & $(-0.20,0.39)$ & -0.04 & $(-0.33,0.25)$ & -0.28 & $(-0.53,-0.03)$ & 0.031 \\
\hline
\end{tabular}

BP, blood pressure; HDL-c, high density lipoprotein cholesterol; MetS-z, metabolic syndrome risk z-score

a Triglycerides was log transformed

b Highest values

c Mean of MetS-z: -0.05 (SE 0.09); mean of MetS-z without waist circumference: -0.04 (SE 0.06), p for heterogeneity $<0.001$

not disappear. The ERICA sample size also allowed us to stratify the sample by weight status, and after that, results regarding the association between adiponectin and MetS-z were materially unchanged.

Our work has some particular observations. We calculated the quartiles of adiponectin adjusted by age and sex, in part because there is not a well-established cutoff point for unhealthy concentrations of adiponectin.
To our knowledge, only two previous studies suggested an optimal cutoff point of adiponectin to detect MetS in adolescents, however both samples were composed of only obese adolescents [16, 37]. We also calculated sex and age-specific continuous MetS z-scored like others $[25,26,38]$, because this increases statistical power. It is a concern in studies with apparently healthy adolescents since the prevalence of MetS is very 


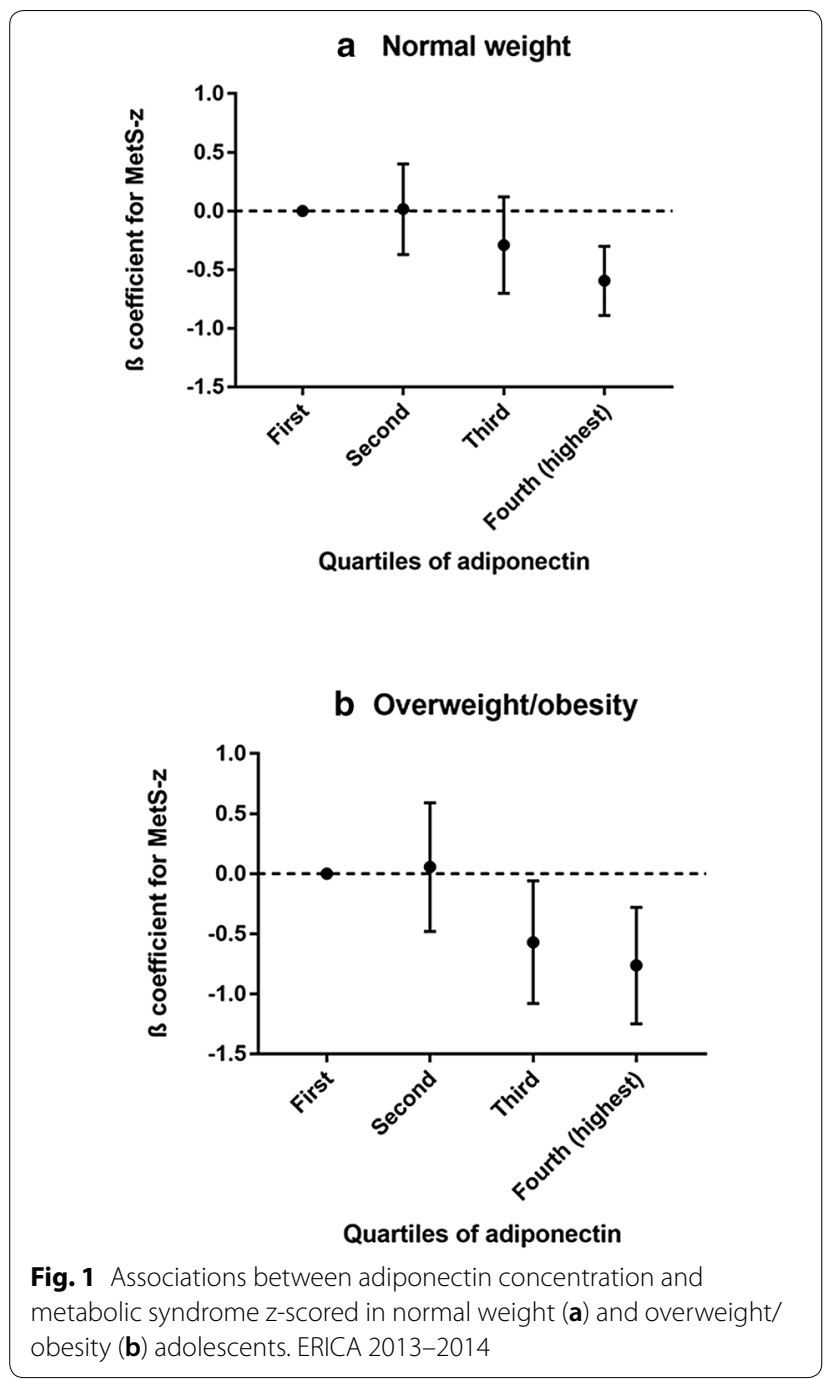

low, considering dichotomized definitions, and MetS z-scored uses full information from the cardio-metabolic risk factors evaluated [39].

Potential limitations of a cross-sectional study include temporal bias. Some of the covariates investigated were self-reported, which can introduce information bias. Furthermore, our analyses were based on a single evaluation of serum adiponectin concentrations, which may increase random measurement error and, consequently, underestimate the observed association. Also, high-molecular weight adiponectin has been suggested to be a better predictor of cardio-metabolic parameters than total adiponectin $[40,41]$, which could have contributed for more conservative results in this study. Finally, adiponectin is one of many biochemical variables related with pro- and anti-inflammatory processes that are produced by adipocytes, and it is not produced equally in all adipose tissues. Furthermore, fat distribution can also interfere in the association of adiponectin with cardio-metabolic outcomes [42, 43].

However, although having some limitations, we believe that our study has several strengths. Most notably, it includes a large, representative and multiethnic sample of adolescents from a developing country. We corrected all analyses for the complex sampling design and adjusted it for a number of potentially important confounding factors, including BMI. In addition, the sample size allowed us to stratify the analyses by weight status. Finally, all biochemical variables, including serum adiponectin concentrations and MetS components, were analyzed using standardized procedures in one central laboratory.

In conclusion, the present results suggests that increased adiposity mediates the association between adiponectin and MetS during adolescence, and this association is attenuated after adjustments for BMI. However, we extended this knowledge using data from a welldeveloped and designed study, which shows that higher adiponectin concentrations are independently associated with MetS risk in Brazilian adolescents, even after adjusting for BMI. These results were similar in normal weight and overweight/obese adolescents, suggesting that adiponectin may play a role in early development of MetS independently of adiposity.

\section{Additional file}

Additional file 1: Table S1. Values of sex and age-specific quartiles of adiponectin. ERICA 2013-2014 $(n=4546)$.

\section{Abbreviations}

MetS: metabolic syndrome; ERICA: Study of Cardiovascular Risk in Adolescents; ELISA: enzyme-linked immunosorbent assay; HDL-c: high-density lipoprotein cholesterol; BMI: body mass index; MetS-z: metabolic syndrome risk z-score.

\section{Acknowledgements}

Not applicable.

\section{Authors' contributions}

KS researched data, analysed data, and wrote the first version of the manuscript. MS wrote and reviewed the manuscript. FVC researched data, analysed data, and edited the manuscript. GHT reviewed the analyses and the final version of the manuscript. LB reviewed the final version of the manuscript. BDS supervised collection of the data, reviewed the analyses and reviewed critically the manuscript. All authors read and approved the final manuscript.

\section{Funding}

Brazilian Ministry of Health (Department of Science and Technology), Brazilian Ministry of Science and Technology (Financiadora de Estudos e Projetos [FINEP01090421]), Conselho Nacional de Desenvolvimento Científico e

Tecnológico (CNPq: 565037/2010-2, 405009/2012-7 and 457050/2013-6). This study was supported by the Research and Events Incentive Fund (FIPE) of the Hospital de Clínicas de Porto Alegre and by the National Institute of Science and Technology for Health Technology Assessment (IATS). 


\section{Availability of data and materials}

The datasets generated and/or analyzed during the current study are not publicly available due to issues in making them accessible online, such as storage difficulties. However, the datasets are available on reasonable request to the corresponding author.

\section{Ethics approval and consent to participate}

The ERICA's protocol was approved by Research Ethics Committees in all 27 Federation units in Brazil. Adolescents were invited to participate in the study at schools and all those enrolled agreed in writing before the data collection. In addition, a written informed consent signed by the parent or legal guardian was collected.

\section{Consent for publication}

Not applicable.

\section{Competing interests}

The authors declare that they have no competing interests.

\section{Author details}

1 Postgraduate Program in Endocrinology, Universidade Federal do Rio Grande do Sul-Hospital de Clínicas de Porto Alegre, Rua Ramiro Barcelos 2350, Prédio 21, $6^{\circ}$ andar, Porto Alegre, RS 90035-003, Brazil. ${ }^{2}$ Postgraduate Program in Cardiology, Universidade Federal do Rio Grande do Sul, Porto Alegre, Brazil. ${ }^{3}$ National Institute of Science and Technology for Health Technology Assessment (IATS), Hospital de Clínicas de Porto Alegre, Porto Alegre, Brazil. ${ }^{4}$ Endocrine Division, Hospital de Clínicas de Porto Alegre, Porto Alegre, Brazil.

Received: 22 February 2019 Accepted: 15 May 2019 Published online: 24 May 2019

\section{References}

1. O'Neill S, O'Driscoll L. Metabolic syndrome: a closer look at the growing epidemic and its associated pathologies. Obes Rev. 2015;16:1-12.

2. Reaven GM. The metabolic syndrome: time to get off the merry-goround? J Intern Med. 2011;269:127-36.

3. Tavares LF, Yokoo EM, Rosa MLG, Fonseca SC. Metabolic syndrome in Brazilian children and adolescents: systematic review. Cad Saude Col. 2010;18:469-76.

4. Magnussen CG, Venn A, Thomson R, Juonala M, Srinivasan SR, Viikari JSA, et al. The Association of Pediatric LDL-cholesterol and HDL-cholesterol dyslipidemia classifications and change in dyslipidemia status with carotid intima-media thickness in adulthood: evidence from the cardiovascular risk in young Finns study, the Bogalusa heart study, and the childhood determinants of adult health (CDAH) study. J Am Coll Cardiol. 2009:53:860-9.

5. Weiss R. Childhood metabolic syndrome: must we define it to deal with it? Diabetes Care. 2011:34(Suppl 2):S171-6.

6. Ebert T, Gebhardt C, Scholz M, Wohland T, Schleinitz D, Fasshauer M, et al. Relationship between 12 adipocytokines and distinct components of the metabolic syndrome. J Clinical Endocrinol Metab. 2018;103:1015-23.

7. Calton EK, Miller VS, Soares MJ. Factors determining the risk of the metabolic syndrome: is there a central role for adiponectin? Eur J Clin Nutr. 2013;67:485-91

8. Sahin-Efe A, Katsikeris F, Mantzoros CS. Advances in adipokines. Metabolism. 2012;61:1659-65.

9. Katsiki N, Mantzoros C, Mikhailidis DP. Adiponectin, lipids and atherosclerosis. Curr Opin Lipidol. 2017;28:347-54.

10. Sparrenberger K, Cureau FV, Telo GH, Schaan BD. Adiponectin levels in Brazilian adolescents: distribution and associated factors in ERICA survey. Clin Chim Acta. 2018;479:126-31.

11. Nappo A, Gonzalez-Gil EM, Ahrens W, Bammann K, Michels N, Moreno LA et al. Analysis of the association of leptin and adiponectin concentrations with metabolic syndrome in children: results from the IDEFICS study. Nutr Metab Cardiovasc Dis. 2017;27:543-51.

12. Vicente SE, Corgosinho FC, Campos RM, Masquio DC, Silva LO, Kravchychyn AC, et al. The impact of adiponectin levels on biomarkers of inflammation among adolescents with obesity. Obes Med. 2017:5:4-10.
13. Jaakkola JM, Pahkala K, Viitala M, Ronnemaa T, Viikari J, Niinikoski H, et al. Association of adiponectin with adolescent cardiovascular health in a dietary intervention study. J Pediatr. 2015;167(353-60):e1.

14. Shafiee G, Ahadi Z, Qorbani M, Kelishadi R, Ziauddin H, Larijani B, et al. Association of adiponectin and metabolic syndrome in adolescents: the caspian- III study. J Diabetes Metab Disord. 2015;14:89.

15. Li P, Jiang R, Li L, Liu C, Yang F, Qiu Y. Correlation of serum adiponectin and adiponectin gene polymorphism with metabolic syndrome in Chinese adolescents. Eur J Clin Nutr. 2015;69:62-7.

16. Liu YL, Liang HR, Liu HT, Li SY, Zhou YY, Cheng HL, et al. Association of serum adiponectin levels with artherosclerosis and the metabolic syndrome in obese children. J Pediatr Endocrinol Metab. 2010;23:743-51.

17. Mangge H, Almer G, Haj-Yahya S, Pilz S, Gasser R, Moller R, et al. Preatherosclerosis and adiponectin subfractions in obese adolescents. Obesity. 2008;16:2578-84

18. Madeira IR, Bordallo MA, Carvalho CN, Gazolla FM, de Souza FM, de Matos $\mathrm{HJ}$, et al. The role of metabolic syndrome components and adipokines in insulin resistance in prepubertal children. J Pediatr Endocrinol Metab. 2011;24:289-95.

19. Riestra P, Garcia-Anguita A, Lasuncion MA, Cano B, de Oya M, Garces C. Relationship of adiponectin with metabolic syndrome components in pubertal children. Atherosclerosis. 2011;216:467-70.

20. Vasconcellos MT, Silva PL, Szklo M, Kuschnir MC, Klein CH, Abreu Gde A, et al. Sampling design for the Study of cardiovascular risks in adolescents (ERICA). Cad Saude Publica. 2015:31:921-30.

21. Cureau FV, Bloch KV, Henz A, Schaan CW, Klein CH, Oliveira CL, et al. Challenges for conducting blood collection and biochemical analysis in a large multicenter school-based study with adolescents: lessons from ERICA in Brazil. Cad Saude Publica. 2017:33:e00122816.

22. Bloch KV, Cardoso MA, Sichieri R. Study of Cardiovascular Risk Factors in Adolescents (ERICA): results and potentiality. Rev Saude Publica. 2016;50:1.

23. Zimmet P, Alberti KG, Kaufman F, Tajima N, Silink M, Arslanian S, et al. The metabolic syndrome in children and adolescents - an IDF consensus report. Pediatric diabetes. 2007:8:299-306.

24. Heshmat R, Heidari M, Ejtahed H-S, Motlagh ME, Mahdavi-Gorab A, Ziaodini $\mathrm{H}$, et al. Validity of a continuous metabolic syndrome score as an index for modeling metabolic syndrome in children and adolescents: the CASPIAN-V study. Diabetol Metab Syndr. 2017;9:89

25. Villa JK, Silva AR, Santos TS, Ribeiro AQ, Sant'Ana LF. Metabolic syndrome risk assessment in children: use of a single score. Rev Paul Pediatr. 2015;33:187-93.

26. Guseman EH, Eisenmann JC, Laurson KR, Cook SR, Stratbucker W. Calculating a continuous metabolic syndrome score using nationally representative reference values. Academic pediatrics. 2018;18(5):589-92

27. Associação Brasileira de Empresas de Pesquisa (ABEP), Critério de classificaçãoeconômica Brasil. http://www.abep.org/criterio-brasil. 2013. Accessed 14 Sept 2015

28. Sallis JF, Strikmiller PK, Harsha DW, Feldman HA, Ehlinger S, Stone EJ, et al. Validation of interviewer- and self-administered physical activity checklists for fifth grade students. Med Sci Sports Exerc. 1996;28:840-51.

29. Farias JCD, Lopes ADS, Mota J, Santos MP, Ribeiro JC, Hallal PC. Validade e reprodutibilidade de um questionário para medida de atividade física em adolescentes: uma adaptação do Self-Administered Physical Activity Checklist. Rev Bras Epidemiol. 2012;15:198-210.

30. de Onis M, Onyango AW, Borghi E, Siyam A, Nishida C, Siekmann J. Development of a WHO growth reference for school-aged children and adolescents. Bull World Health Organ. 2007:85:660-7.

31. Valsamakis G, Chetty R, McTernan PG, Al-Daghri NM, Barnett AH, Kumar $S$. Fasting serum adiponectin concentration is reduced in Indo-Asian subjects and is related to HDL cholesterol. Diabetes Obes Metab. 2003:5:131-5

32. Papoutsakis C, Yannakoulia M, Ntalla I, Dedoussis GV. Metabolic syndrome in a Mediterranean pediatric cohort: prevalence using International Diabetes Federation-derived criteria and associations with adiponectin and leptin. Metabolism. 2012:61:140-5.

33. Shaibi GQ, Cruz ML, Weigensberg MJ, Toledo-Corral CM, Lane CJ, Kelly LA, et al. Adiponectin independently predicts metabolic syndrome in overweight Latino youth. J Clin Endocrinol Metab. 2007;92:1809-13.

34. Ntzouvani A, Fragopoulou E, Panagiotakos D, Pitsavos C, Antonopoulou S Reduced circulating adiponectin levels are associated with the metabolic 
syndrome independently of obesity, lipid indices and serum insulin levels: a cross-sectional study. Lipids Health Dis. 2016;15:140.

35. Kynde I, Heitmann BL, Bygbjerg IC, Andersen LB, Helge JW. Hypoadiponectinemia in overweight children contributes to a negative metabolic risk profile 6 years later. Metabolism. 2009;58:1817-24.

36. Perez CM, Ortiz AP, Fuentes-Mattei E, Velazquez-Torres G, Santiago D, Giovannetti K, et al. High prevalence of cardiometabolic risk factors in Hispanic adolescents: correlations with adipocytokines and markers of inflammation. J Immigrant Minor Health. 2014;16:865-73.

37. Gilardini L, McTernan PG, Girola A, da Silva NF, Alberti L, Kumar S, et al. Adiponectin is a candidate marker of metabolic syndrome in obese children and adolescents. Atherosclerosis. 2006;189:401-7.

38. Ejtahed HS, Qorbani M, Motlagh ME, Angoorani P, Hasani-Ranjbar S, Ziaodini $\mathrm{H}$, et al. Association of anthropometric indices with continuous metabolic syndrome in children and adolescents: the CASPIAN-V study. Eating Weight Disorders. 2017;23(5):597-604

39. Andersen LB, Lauersen JB, Brond JC, Anderssen SA, Sardinha LB, SteeneJohannessen J, et al. A new approach to define and diagnose cardiometabolic disorder in children. J Diabetes Res. 2015;2015:539835.

40. Lara-Castro C, Luo N, Wallace P, Klein RL, Garvey WT. Adiponectin multimeric complexes and the metabolic syndrome trait cluster. Diabetes. 2006;55:249-59.
41. Murdolo G, Nowotny B, Celi F, Donati M, Bini V, Papi F, et al. Inflammatory adipokines, high molecular weight adiponectin, and insulin resistance: a population-based survey in prepubertal schoolchildren. PLOS ONE. 2011;6:e17264.

42. Frederiksen L, Nielsen TL, Wraae K, Hagen C, Frystyk J, Flyvbjerg A, et al. Subcutaneous rather than visceral adipose tissue is associated with adiponectin levels and insulin resistance in young men. J Clin Endocrinol Metab. 2009;94:4010-5.

43. Reneau J, Goldblatt M, Gould J, Kindel T, Kastenmeier A, Higgins R, et al. Effect of adiposity on tissue-specific adiponectin secretion. PLOS ONE. 2018;13:e0198889.

\section{Publisher's Note}

Springer Nature remains neutral with regard to jurisdictional claims in published maps and institutional affiliations.
Ready to submit your research? Choose BMC and benefit from:

- fast, convenient online submission

- thorough peer review by experienced researchers in your field

- rapid publication on acceptance

- support for research data, including large and complex data types

- gold Open Access which fosters wider collaboration and increased citations

- maximum visibility for your research: over $100 \mathrm{M}$ website views per year

At BMC, research is always in progress.

Learn more biomedcentral.com/submissions 